University of Wollongong

Research Online

Faculty of Social Sciences - Papers (Archive) Faculty of Arts, Social Sciences \& Humanities

$1-1-2016$

Exploring Engineering instructors' views about writing and online tools to support communication in Engineering

Sarah Katherine Howard

University of Wollongong, sahoward@uow.edu.au

Maryam Khosronejad

University of Sydney

Rafael Calvo

University of Sydney, rafael.calvo@sydney.edu.au

Follow this and additional works at: https://ro.uow.edu.au/sspapers

Part of the Education Commons, and the Social and Behavioral Sciences Commons

Research Online is the open access institutional repository for the University of Wollongong. For further information contact the UOW Library: research-pubs@uow.edu.au 


\title{
Exploring Engineering instructors' views about writing and online tools to support communication in Engineering
}

\author{
Abstract \\ To be fully prepared for the professional workplace, Engineering students need to be able to effectively \\ communicate. However, there has been a growing concern in the field about students' preparedness for \\ this aspect of their future work. It is argued that online writing tools, to engage numbers of students in the \\ writing process, can support feedback on and development of writing in engineering on a larger scale. \\ Through interviews and questionnaires, this study explores engineering academics' perceptions of writing \\ to better understand how online writing tools may be integrated into their teaching. Results suggest that \\ writing is viewed positively in the discipline, but it is not believed to be essential to success in \\ engineering. Online writing tools were believed to support a larger number of students, but low knowledge \\ of the tools limited academics' understanding of their usefulness in teaching and learning. Implications \\ for innovation in undergraduate teaching are discussed.
}

\section{Keywords}

support, tools, online, writing, about, communication, views, exploring, instructors, engineering

\section{Disciplines}

Education | Social and Behavioral Sciences

\section{Publication Details}

Howard, S. K., Khosronejad, M. \& Calvo, R. A. (2017). Exploring Engineering instructors' views about writing and online tools to support communication in Engineering. European Journal of Engineering Education, 42 (6), 875-889. 


\section{Exploring academics' perceptions of writing and online tools to support communication in Engineering}

Sarah K. Howard ${ }^{\mathrm{a}}$, Maryam Khosronejad ${ }^{\mathrm{b}} \&$ Rafael Calvo $^{\mathrm{c}}$

${ }^{a}$ School of Education, University of Wollongong, Wollongong, Australia

${ }^{b}$ Faculty of Education and Social Work, The University of Sydney, Sydney, Australia

${ }^{c}$ School of Electrical and Information Engineering, The University of Sydney, Sydney, Australia

Corresponding author:

Dr Sarah K. Howard

Faculty of Social Sciences

University of Wollongong NSW2522

Australia

+61(0)2 42213664

sahoward@uow.edu.au

Word count: 6,437 excluding figures, tables and references

\section{Acknowledgements}

This work was supported by an Australian Office for Learning and Teaching Innovation Grant

(2013-2015; OLT-ID12-2409) 
To be fully prepared for the professional workplace, Engineering students need to be able to effectively communicate. However, there has been growing concern in the field about students' preparedness for this aspect of their future work. It is argued that online writing tools, to engage numbers of students in the writing process, can support feedback on and development of writing in engineering on a larger scale. Through interviews and questionnaires, this study explores engineering academics' perceptions of writing to better understand how online writing tools may be integrated into their teaching. Results suggest writing is viewed positively in the discipline, but it is not believed to be essential to success in engineering. Online writing tools were believed to support a larger number of students, but low knowledge of the tools limited academics' understanding of their usefulness in teaching and learning. Implications for innovation in undergraduate teaching are discussed.

Keywords: technology integration, writing, online feedback, Engineering education, higher education

\section{Introduction}

The practice of engineering is now commonly described as one of 'communication, teams, and multiple fields impinging on design solutions, as well as a world of engineering science fundamentals and design and manufacturing practices' (Dunsmore, Turns, and Yellin 2011, 331). In the current global professional domain, recent university graduates are required to write proposals, communicate with distributed teams, deliver products and documentation that can be easily understood by multiple audiences (Boiarsky 2004). There has been international concern in engineering developing over several decades that university graduates are not well prepared in this area. Moreover, innovation and change in undergraduate education tackling this issue has been limited (Gassman, Maher, and Timmerman 2013). To address this concern, the current paper investigates academics perceptions of writing and the possible use of online writing tools to support students' developing communication skills in undergraduate Engineering. The aim of this investigation is to better understand academics' perceptions of writing and how this relates 
to possible use of online writing tools, to support communication and writing development in undergraduate Engineering.

In recent years, universities have introduced a range of online tools, such as TurnItIn and Moodle, with the capacity and functionality to support communication and writing development. However, little is actually known about how engineering academics conceive of writing and written assessments, and therefore how and why they may adopt online writing tools in their practice. This paper argues that affordances of online tools can support increased writing and communication in undergraduate engineering subjects. To explore this, we first present a discussion of current research on writing in undergraduate engineering, online writing tools and some common affordances. Analysis draws on data collected from engineering academics at three Australian universities, through semi-structured interviews and online questionnaires between 2013 and 2014. Data was first inductively analyzed using a repertory grid method (RGT) to identify academics' perceptions of writing through personal constructs (Fransella, Bell, and Bannister 2004). Using extracted RGT constructs and drawing on the Technology Acceptance Model (TAM) conceptual framework of Ease of Use, Usability and Attitudes, two academics' beliefs about the use of written assessments and relation to online writing tools are explored to illustrate different views and likelihood of adopting online writing tools. Implications for future research and strategies for universities will be discussed.

\section{Writing in Engineering}

Educators have long proposed that writing is a powerful way of learning (Emig 1977) and continued to advocate for its wider adoption across curriculum (Carter, Ferzli, and Wiebe 2007; Wheeler and McDonald, 2000). Writing is a legitimate practice in itself, but also provides opportunities to enhance generic thinking skills and conceptual understanding in discipline areas 
(Wheeler and McDonald 2000). While engineering students do not typically enter the discipline for love of writing, it is an essential skill in the profession (Lievens 2012). Questions of supporting writing development become increasingly important when supporting growing international student populations to effectively communicate in English (Lax 2014).

Previously engineering was thought to be an isolated and unsocial field, but over the last few decades it has changed. The social aspect of engineering is now recognised along with other engineering dimensions including science, design, and practical realisation (Figueiredo 2008). Engineering work has become more collaborative and horizontal (Lievens 2012). Writing is now regarded as a central practice in the work of engineers who need to communicate their technical knowledge to a broad variety of audience (Boiarsky 2004; Leydens and Schneider 2009; Wheeler and McDonald 2000). However, while Riley et al.'s (2000) found that 38\% of recent engineering graduates felt communication and writing skills were one of the most important factors in their profession, it was also the area where they felt least prepared.

There have been a growing concern in governments and professional bodies (Nair and Patil 2008), and at the university, about engineering graduates' communication skills and their preparedness to fully participate in the industry (Ford and Riley 2003; Gassman et al. 2013). There are a number of barriers to the adoption of written tasks in engineering subjects. Two key issues are being difficult to manage in large undergraduate subjects (Heylen and Vander Sloten 2013) and lack of value in the discipline (Rendahl and Breuch 2013; Waycott et al. 2010). These perceived barriers are commonly understood as first and second order, respectively (Ertmer 2005). First order barriers encompass logistical issues, while second order barriers deal with deeper value systems relating to beliefs about teaching and beliefs about specific digital technologies. 


\section{Online writing tools}

In Engineering, while computer-based approaches to learning are used often, online tools to support writing have not been common (Drury, O'Carroll, and Langrish 2006). Given that Engineering students may have depth and breath in content knowledge, undergraduates have 'very limited understanding of disciplinary writing' (Gassman et al. 2013, 1270). Therefore, it is important that engineering academics actively support students in engineering to develop their writing (Leydens and Schneider 2009). Exploratory research in this area has shown that students were likely to make higher quality changes in their work when teachers' provide feedback questioning their work (Alvarez et al. 2011; Wheeler and McDonald 2000). In a face-to-face learning environment, collaboration and/or feedback may involve a teacher or a peer, and would typically be done in small groups. This approach to learning can be highly interpersonal, but it can also be difficult to negotiate in large groups (Qiu et al. 2014). Online writing tools provide one way to do this more efficiently and with more focused feedback.

Over the past decade, a wide range of online technologies has been introduced into universities that can support writing. While these different forms of online learning have been well accepted in higher education, implementation in teaching has been slow (Mitchell and Geva-May 2009). Some of the tools now commonly available are TurnItIn (Rolfe 2011), written feedback tools in learning management systems (LMS; Ellis 2011), Google Apps (Karpova, Correia, and Baran 2009) and custom-build platforms (Rikakis, Tinapple, and Olson 2013). These tools are able to support writing, through online feedback, peer reviewing, collaboration, and writing support. Some tools provide automated feedback and visualizations generated using Natural Language Processing techniques (Calvo 2015; Calvo et.al 2011). Online writing tools 
may be used collaboratively or individually (Alvarez, Espasa, and Guasch 2011; Qiu, Hewitt, and Brett 2014).

However, encouraging adoption of new digital technologies and teaching strategies can be difficult. In many universities engineering academics are 'justifiably concerned' that work developing new curriculum integrating writing and collaborating will not contribute to their advancement in the field (Leydens and Schneider 2009; Waycott et al. 2010). Further, writing may not be viewed as relevant to their teaching context. Academics' and faculty conceptions of skills, content and practices that are of value in the discipline are translated to students, whose development and outcomes are likely to be affected by these beliefs (Umbach and Porter 2002). Moreover, changing practice is difficult and concerning for many educators (Mitchell and GevaMay 2009). The mere availability of new digital tools or knowledge of strategies is rarely sufficient to motivate innovation and change in teaching and learning. To support innovation and adoption of new teaching practices and digital technologies, values and beliefs of teaching, learning and technology need to be identified and understood.

\section{Conceptual framework}

The purpose of this study was to investigate academics' perceptions of writing and the possible use of online writing tools and how this may support students' developing communication skills in undergraduate Engineering. The specific research questions for this investigation were:

i) What are academics' perceptions of written assessments in undergraduate Engineering, and ii) How may academics' perceptions of writing affect their adoption of online writing tools in teaching and learning? 
Adoption of online writing tools includes considerations of attitudes and conceptions of both writing and online tools within undergraduate engineering. Some reasons for slow change and rate of adoption will relate to academics' knowledge of communication and writing in the discipline (Gassman et al. 2013), support and time to change their teaching (Boiarsky 2004), and beliefs and values about importance and relevance (Ertmer 2005; Leydens and Schneider 2009). Values and beliefs can be collectively understood as 'attitudes.' Attitudes can be understood as an affective response related to cognitive responses to ease of use and usefulness of a technology (Davis 1989).

Ajzen's $(1985,1991)$ theory of planned behaviour explains the relationship between attitudes and behaviour as the expectancy-value model. Briefly, if a person holds positive beliefs about the outcome of a behaviour, they are more likely to engage in it. This model has been widely applied and has reliably proved that attitudes are predictive of behaviour (Straub 2009). However, Davis (1989) theorized that the expectancy-value model for technological innovation was slightly different. He argued that a Technology Adoption Model (TAM), addressing adoption of a new tool or system, would include attitudes, but also perceptions of 'ease of use' and 'usefulness' of the technology. Perceived usefulness refers to the extent in which an individual believes a process or system will support their job performance and perceived ease of use is defined as the degree in which an individual believes a system is free from effort. In this discussion, the implementation of online writing tools is the technological innovation considered. The TAM has been modified and developed in a number of ways since Davis's (1989) original work (e.g. TAM2, Venkatesh and Davis 2000). The current study uses the basic conceptual framework of the TAM as an organizer to inform inductive analysis of academics' perceptions of writing in Engineering. The aim is to develop a better understanding of possible integration of 
online writing tools in undergraduate learning.

\section{Method}

The study presented in this paper is part of a larger Australian Office for Teaching and Learning Innovation Grant, examining undergraduate Engineering teaching in three Australian universities. The overall aim of project was to explore the use of online writing tools in undergraduate engineering teaching and learning. The current analysis specifically considers some of academics' perceptions of writing and considers how these may relate to uptake and integration of online writing tools in teaching and learning.

The research was conducted in two stages. The first stage addressed the first research question, and explored academics' perceptions of writing. It was designed using the Repertory Grid Theory (RGT) method. A repertory grid is a way to view personal constructs; the method is designed to elicit these constructs (Fransella et al. 2004). A construct is ' ... a way in which some things are construed as being alike and yet different from others' (Kelly 1991, 74). Constructs are said to be bipolar because meaning is created not only by defining what something is, but also by contrasting it from what it is not. For example, an individual may describe a neighbour to be a 'peaceful' person. But 'peaceful' could be contrasted either with 'noise' or 'easily agitated.' Thus to understand what the individual means by peaceful, we need to know the opposite pole of the construct. In this method, individuals are presented with a variety of elements that may relate to topic, practice or belief. Through comparison and contrasting how elements can be distinguished from each other constructs are identified. These differences and similarities can then be compared across and within groups, in a range of statistical ways. This procedure (called a 'minimum context form' [Curtis et al. 2008, 43]) is performed to elicit constructs. The RGT method is appropriate for small sample numbers, to inform decisions and identify perceptions, 
but it is also appropriate for larger sample sizes to investigate generalizability of constructs (Aditomo et al. 2011).

There is a long history of researchers applying the repertory grid method in other contexts and for different research objectives. In organizations, researchers have used the method to understand how employees perceive the managerial styles in their departments (Honey 1979). Constructs elicited in such a study could include 'good at delegating vs. likes to do work by himself' or 'flexible vs. rigid'. In education, teachers could apply repertory grid methods to evaluate whether and how students' views about a phenomenon under study has changed (or has not) after instruction (Keynan, Assaraf, and Goldman 2013). Additionally it could be used to explore how students or teachers perceive different forms of learning tasks, assessment methods, and technologies (Aditomo, Calvo, and Reiman 2011).

In this discussion, the method is employed to understand how engineering academics perceive writing as an assessment type and in relation to three other types of assessments. To address the second research question, concerning how perceptions of writing may affect adoption of online writing tools, RGT constructs and the TAM were used as a combined conceptual framework to guide theoretical content analysis of academics' elicitations relating to undergraduate teaching, writing and use of online writing tools (see Flick, 2000).

\subsection{Sample}

The three Australia universities participating in this research were located in metropolitan and were all teaching and research institutions. Engineering academics from all sub-disciplines of Engineering were included in the sample. The sampling strategy for the interviews was purposive, in that multiple academics representing the three approaches to written assignment management were identified. The questionnaire was a snowball approach, within the purposive 
sample. Engineering academics at the three universities were invited to participate in the study, until a sample of 30 was achieved, which is necessary to conduct one-sample t-tests and one-way analysis of variance (ANOVA).

\subsection{Data collection}

Data included in this paper were collected in late 2013 and early 2014, through interviews and a questionnaire. First, to investigate these questions, RGT interviews were conducted with academics from each of the participating universities. Academics were selected based on their approaches to written assessments was identified: i) those using a university Learning Management System to support writing, ii) those currently using an online writing tool, and iii) those using a paper-based system. Each interview was approximately 45 minutes and comprised two main sets of: i) repertory grid elicitation of assessment constructs (elements: written assessment, multiple-choice exam, presentation and project) and constructs of approaches to written tasks (elements: LMS, online writing tools and paper-based) and ii) episodic questioning about use of written assignments and beliefs about writing and online writing tools (see Flick 2000).

The elicitation of perceptions of assessment types was the focus of this analysis. Assessment tasks were identified through analysis of subject outlines from the three universities. Four common assessment tasks were identified: written assignments/essays, multiple-choice exams, oral exams/presentations and projects. Interview participants were asked to consider how assessment task types were similar or different. This procedure was demonstrated with an example of: taxi/car/bus as elements; the construct being that taxi and car are similar because they are private, while a bus is public. The elements (assessment types) were: i) written assignment/essay, ii) multiple-choice exam, iii) oral exams/presentation and iv) projects. For 
each grouping of the elements, the interviewer wrote down the construct and asked the participant to confirm it was correct.

The second part of the data collection was a pilot questionnaire, to compare constructs among assessment types. Like the interviews, the questionnaire included three main sections: i) items addressing constructs of assessment, ii) constructs used to investigate online tools and iii) concerns measure addressing use of online tools in teaching and learning. The first two sections were derived from analysis of academics' interviews considering perceptions of assessments (see first part of data collection). The third section was derived from Kwok's study of teachers' concerns (see Kwok 2014). The questionnaire included 130 items in total. Thirty-six of the items addressed writing, 24 of which were based on constructs elicited through the interviews. Likerttype scales were used in the elicitation items, using the construct for the opposing ends of the scale (see Table 1).

$<$ insert Table 1 here $>$

The questionnaire was conducted online (using Google Forms). It was distributed to Engineering academics at the three universities through email invitations to participate including a URL to the questionnaire, sent by deans of faculties or heads of school at each university.

\subsection{Analysis}

The RGT analysis of the interviews and analysis of the questionnaire data address the first research questions, concerning academics' perceptions of written assessments in undergraduate Engineering, First, interviews were inductively analysed and common constructs identified. In the interview, participants were asked to group similar assessment tasks and then discuss why they are similar and others are different. They were then asked to label this difference, which formed the basis for triangulation. An example of this is the construct of 
assessment management. Some participants felt assessments were 'easy to manage' and some felt they were 'difficult to manage.' Easy and difficult became poles of distinction. This process was repeated for all combinations of the elements. Constructs identified were then used to develop the pilot questionnaire. The poles of distinction were used as high and lows of Likerttype scales, e.g. the assessment is: easy to manage <---1---2----3---4---5--> difficult to manage (see Table 1). To select meaningful constructs from the questionnaire responses, an ANOVA was conducted. Assessment Type was treated as the independent variable and constructs were treated as dependent variables. Nine constructs demonstrated significant main effects of Assessment Type and were selected for further examination.

Using the nine constructs, the second stage included a qualitative analysis of two academics' use and perceptions of writing and online tools to address the second research question. A comparison of the two academics is used to illustrate how conceptions may inform future use of online writing tools. A combined framework of RGT constructs and the TAM (Usefulness, Attitudes and Ease of Use) were used as a basis for theoretical coding of two academics interviews. Two academics were selected as illustrative examples of i) different conceptions of writing, ii) how RGT constructs related to their likelihood of adopting online writing tools. While interviews were theoretically coded on the nine constructs, thematic coding was also conducted to consider additional emergent categories. In the first step of the analysis, the nine constructs were considered relation to Usefulness, Attitudes and Ease of Use. This allowed for beliefs about written assessments, teaching and learning to be identified. In the second step of analysis, these beliefs were considered in relation to likelihood of changing their practice and adopting online writing tools. Interviews were independently coded by two 
researchers. Inter-rater reliability was conducted to ensure consistency of analysis and discrepancies in the analysis were discussed until 100\% agreement was achieved.

Importantly, this approach provided a method of exploring the nature of, and then comparing and contrasting, the constructs (Fransella et al. 2004). The interviews were able to provide rich data explaining the constructs, while the questionnaire supported wider investigation of the validity of these constructs. In the following section, academics' use of written assessments is presented first, followed by presentation and discussion of the nine constructs and four assessment types.

\section{Results}

Nine Engineering academics participated in the interviews: four from University 1, three from University 2 and two from University 3. Participants were from the areas of Civil, Electrical, Mechanical, Mining and Systems Engineering. Academics reported using a mixture of writing task management, typically paper-based and LMS in their subjects. One academic was using online writing tools. One had also used TurnItIn, but only for plagiarism and not for providing feedback to students.

Each interview elicited between 5 and 20 constructs relating to use of the four assessment types in undergraduate Engineering. For the purposes of this analysis, we considered the total 96 constructs elicited. Constructs were then grouped into categories based on similarity of meaning (see Aditomo et al., 2011). From this, 11 main categories were identified: timespan/time constraint, students' level of understanding, structure of student response, demand on instructor, nature of expected response, student agency, assessment of communication/skills, response format, collaborative nature, teacher-student interaction, industry preparedness and social formality. Four of these categories were eliminated for lack of relevance to writing. The final 
seven categories and their related constructs were used to develop the questionnaire (see Appendix 1).

\subsection{Academics' use of writing assignments}

Thirty academics completed the questionnaire: 17 from University 1, nine from University 2 and three from University 3. Participants were from the areas of Biomedical, Civil, Electrical, Mechanical, Mining and Systems Engineering. For $73 \%$ of participants it was 'encouraged' or 'strongly encouraged' for them to increase the amount of feedback they provide to students on assessments. For the purpose of the questionnaire, participants were asked to nominate one subject they were teaching or had recently taught. Of the 30 participants, 26 reported using written assignments in their subjects, 10 used multiple-choice exams, 16 used presentations and 15 used projects. One of the academics was not using written assignments. Their subject was 'purely mathematical and attempts in the past to include written assignments were entirely artificial,' another cited the 'marking burden' of written assignments was too prohibitive. A third participant felt other skills were 'more essential for Engineering.'

The length of the written products ranged from very short reflective tasks of 400 to capstone projects of 35,000 words. Written tasks had a median of 3,000 words. The longest was a group assignment in the form of a feasibility report on a mining project. Sixteen participants said they provided students with a structure and/or headings for the written assignment. Twenty indicated that the writing was an individual assignment; two involved group work and four were a mixture of the two. Over half of the academics reported using the university LMS to manage written assignments (17), 10 of the academics were using paper-based systems and seven were having students submit written tasks via email. However, for 12 of the participants it was 'mandatory' for them to use the university LMS and 'strongly encouraged' for another 10. 


\subsection{Comparison of four forms of assessment}

The nine constructs demonstrating a main effect of Assessment Type are presented in Table 2. <<insert Table 2 here >

These constructs were qualitatively grouped into three categories, based on the TAM. Figure 1 presents participants' perceptions of the Usefulness as an assessment tool. <<insert Figure 1 here >

One-way ANOVA indicated statistically significant differences between the assessment forms for all three dimensions of Usefulness: communication skills, $F(3,84)=68.48, p<.01$; technical knowledge, $F(3,84)=8.02, p<.01$; and, research skills, $F(3,84)=21.81, p<.01$. On all three constructs, written assignments were perceived to be the most useful. Overall, multiplechoice exams were the least useful at assessing communication and research skills. The least amount of difference on the four assessment types was in assessing technical knowledge, but presentations were significantly less than writing. These findings suggest that written assignments were generally perceived as more useful than the other three types.

Figure 2 presents Attitudes towards value of each assessment type in learning.

$<<$ insert Figure 2 here $>>$

Differences between the assessment forms for all three dimensions of Attitudes were: deep understanding, $F(3,84)=36.86, p<.01$; importance for industry, $F(3,84)=49.41, p<.01$; and, motivating, $F(3,84)=24.20, p<.01$. Results demonstrate that academics valued multiplechoice exams the least on all three constructs. However, while writing was comparable with presentations and projects in regard to importance for industry and being motivating, it was valued less on both. This finding is consistent with evidence that students do not value writing 
and would therefore not find it motivating (Lievens 2012), which suggests academics were relatively accurate in this perception. Projects were seen as having the most value in learning.

Figure 3 presents beliefs about the Ease of Use of each type of assessment. <<insert Figure 3 here>>

Differences between the assessment forms for all three dimensions of Ease of Use were: easy to create, $F(3,84)=12.98, p<.01$; easy to use in large classes, $F(3,84)=34.75, p<.01$; and, easy to mark, $F(3,84)=50.18, p<.01$. It can be observed that multiple-choice exams, while perceived as more difficult than written assessments to create, were thought to be the easiest to use in large classes and the easiest to mark. This result reflects a commonly held belief that multiple-choice exam are an efficient method of assessment, but do not provide a way for students to demonstrate a depth of knowledge. This triangulates with academics' less positive attitudes towards the value of multiple-choice assessments (see Figure 2).

Overall, written assessments were seen as the most useful assessment type, but not the most valued. Academics felt more positive towards projects and presentations than written assessments, but projects and presentations were seen as more difficult to create and slightly more difficult to use in large classes. Writing was considered the most difficult to mark. However, to understand how Attitudes, perceived Usefulness and Ease of Use affect use of writing in teaching and learning, the interaction of these constructs must be examined. In the following section we present an analysis of two academics' perceptions of writing in teaching and learning, and how this may relate to their uptake of online writing tools.

\subsection{Comparison of two academics}

In this section, we address research question two using two cases to illustrate similarities and differences in perceptions about writing and use of online tools for assessment purposes. These 
two examples are not intended to be representative of engineering academics, but simply to present two different views of writing in engineering in relation to constructs of Attitudes, perceived Usefulness and Ease of Use. To deepen understanding of these constructs, academics were asked in the interviews to discuss, beliefs about writing, what was a 'successful student' in Engineering and how they managed written assessments.

\subsubsection{Academic One}

Academic one was a lecturer in mining engineering. He taught a range of subjects across the four years of undergraduate study, including a capstone project. He chose to discuss the capstone subject for the interview. The capstone subject aimed to prepare students for industry and develop their understanding of the field. The main assessment was an authentic 'design project,' related to the professional experience in mining engineering. Assessment included progress interviews with groups of students, a final presentation and submission of a written report. He identified the main aim of design projects as collaboration. He felt writing was an important component of the design project, but it was to facilitate the project rather than fostering deeper understanding of Mining Engineering.

In describing a successful engineer he believed:

Apart from understanding the engineering skills and things like that, I guess communication is a big skill, I mean, and when I say communication it is specifically not just writing well or speaking well, but also be a team player and that's very important, especially in the mining sector, because there is a lot of communication.

Comments suggest that he held the attitude that success in Engineering directly related to communication skills, but this did not necessarily mean written communication. This belief was 
reflected in the aim of the design project being collaboration and writing as a component of that work. He elaborated on this attitude in relation to usefulness of written assessments:

[With writing] one of the main drawbacks is obviously if it's a group project, ... I think it misses out some of the students' communications skills... Because it's one document that gets submitted.

He did not believe that a written assessment captured collaboration, which he identified as a key aspect of success and assessment. He identified complementary ways of assessment, such as peer reviewing and online surveys, to gather information regarding students' collaboration and if they have been a 'team player.' He did not specifically identify if he used these additional methods.

He used PDF documents as a way to give feedback and mark written assessments. He found this to be a useful and easy way to do his marking 'whenever and wherever' he wanted. He elaborated, saying

students have to pay for their printing [when using paper based assessment]... so if I can mark it online, why ask them to pay for their printing and things like that?

Rationale for using PDFs reflected a relatively pragmatic view of this strategy. He held positive attitudes about online writing tools, but he did not use them. He felt these tools could provide useful feedback to students to help them develop their writing, and that they would save him time:

...passing it on to all the students, so that they can improve [their writing] in their next report...I haven't used iWrite [online writing tool] much but what my understanding is it does a bit of the grammatical marking, the spelling on its own. So, it requires less of my time to do that... [I know] there [are] tools in LMS where you can mark, I don't use that, but I just use my old PDF writer to do all the marking. 
He did not express willingness to change his current practice of electronic marking. $\mathrm{He}$ held positive attitudes about the usability of online tools to support writing. Yet, he believed that the PDF method was the easiest approach to marking written assessments, he felt comfortable using the PDF system, and he did not feel he needed to change. Academic 1's reflection on writing and use of written tasks in Engineering aligned with the questionnaire results, where he reported higher than average perception of Ease of Use of writing and an average Attitude. He reported some knowledge of online writing tools and a pragmatic view of usefulness, based on ease of use. His attitude did not significantly relate to benefits of developing students' writing or their learning.

\subsubsection{Academic Two}

Academic two was a subject coordinator in the School of Chemical and Biomolecular Engineering for a number of subjects including advanced engineering, management of technology, and international engineering strategies and operations. Most of the subjects he coordinated had common learning outcomes such as information seeking, communication and teamwork, design and professional conduct. For the interview, he chose to discuss a technology management subject. Learning outcomes included communication skills and information seeking. For assessment purposes, he used a combination of written reports and presentations. He felt that written tasks were a useful way to assess these skills.

He described successful engineers having:

... a broad understanding of the world and all the forces that shape in everyday and macrolevel interactions, and see that they can play a significant role in making the world a somewhat better place. 
His beliefs about success in engineering reflected a broad world-view and the individual's role in that place. He went on to elaborate that a successful engineer would also have depth knowledge, and 'understand constraints and limitations.' He expressed positive attitudes towards the use of writing to support development of this view in students. He specifically believed written assessments would:

...allow for qualitative exploration suitable for addressing complexities of the world with varieties of shades... writing takes students into the world of intellectual inquiry where one thinks about an argument.

Comments suggest that writing provided a way for students to engage in inquiry of the world and provided a way to learn through inquiry and exploration. He also described writing as an act of persuasion, which he believed was always beneficial to students' learning. This suggests a close relationship between his attitudes, usefulness and use of written tasks in his teaching. Writing was believed to be useful as a way to engage with arguments, and he held the attitude that it was of benefit to students' learning. These beliefs also align with belief about success in engineering, in that writing supported students to understand complexities and interactions of the world.

Overall, he believed there were no drawbacks to writing as an activity and task in engineering. However, he did identify that some international students struggled with writing. He emphasises that:

the issue is people's skills with language... People whose, their English is a second language, that's an obvious challenge there, just a challenge.

He felt this issue presented a challenge, rather than being a limitation of writing. This suggests his positive attitude towards writing and usefulness, supported the importance of writing for all 
students. In terms of using online tools, he used the university LMS for assessment, in most cases. He further adds that he uses mixed forms of paper-based and online form in small classes:

...students and certainly some tutors feel that traditional one where you write lots of comments on a ... paper and are able to follow it and go back and forth more easily. So in the end we combine the two.

Academic 2 did not make a connection between use of the LMS to manage written assessments and development of students' writing. His shift in practice to a paper-based approach, to support feedback between tutors and students, demonstrates a relation between the usefulness of feedback and how students may develop their writing. This comment shows some alignment with attitudes about writing and use of certain assessment management strategies. In his questionnaire responses he reported little to no knowledge of online writing tools. He also reported higher positive beliefs about the usefulness of writing to support deeper understanding.

\section{Discussion}

This paper has examined academics perceptions of writing; to better understand how online writing tools could be adopted in undergraduate engineering subjects. In regard to the first research question, questionnaire results showed that academics rated writing higher in relation to Usefulness as compared with other forms of assessment. However, participants had less positive Attitudes about writing and felt it was difficult to manage in large classes. Particularly, they valued writing less for assessing deep understanding and importance for industry than projects. This result has implications for motivation of academics to adopt new teaching strategies, if other forms of assessment are more valuable and easier to implement (Gassman et al. 2013; Heylen and Vander Sloten 2013; Rendahl and Breuch 2013). 
In regard to the second research question and potential to adopt online writing tools, findings showed that academics had little knowledge of online writing tools. This reflects agreement with other research in the area (e.g. Drury, O'Carroll, and Langrish 2006; Mitchell and Geva-May 2009). However, while currently only limited to the two illustrative case studies, interview results suggest deeper beliefs about the importance of writing in relation to success in engineering would positively influence future integration of online tools. This finding was shown through analysis of Academics 1 and 2 considering how academics' perceptions of written assessments in undergraduate engineering may relate to future adoption of online writing tools. Both Academics 1 and 2 held positive attitudes about writing. However, the main comparison between the two was beliefs about the role of writing in engineering. Academic 1 saw writing as a component of being a successful engineer, which suggests a finite view of writing's usefulness in teaching and learning. Consequently, writing was discussed as a component of teaching practice and one aspect of assessment. Academic 2 saw writing as part of successful engineer's core understanding of the world. His comments suggest a broader and more integral attitude towards the usefulness of writing. His belief that writing facilitated engagement with and inquiry of complex ideas reflected his basis of success in engineering. This resulted in writing being at the core of his assessment practices. This suggests implications for undergraduate teaching practice related to conceptions of writing as an assessment task and writing as a skill for being a successful engineer.

We conclude that differences between the two academics' Attitudes and perceptions of Usefulness, affected their perceptions of Ease of Use in managing written tasks in their subjects. Academic 1's discussion of writing's Usefulness was mostly pragmatic and did not include students receiving feedback and developing their writing. For the design project, he assessed 
their written report for evidence of professional experience and collaboration. This suggests that for Academic 1, the decision not to use online writing tools (which he was aware of) was based on conceptions of what was most useful. In the case of Academic 2, he did not have knowledge of online writing tools. However, he did identify the importance of students receiving good feedback on their writing, but this was limited to small classes. It is possible that his perceptions of usefulness and positive attitudes about feedback in writing would align with use of online writing tools. Given the affordance of online writing tools to support feedback in larger cohorts of students, this may be an avenue of development for Academic 2.

\section{Conclusions and future research}

In conclusion, findings illustrate certain constructs of writing, such as how it contributes to students' future engineering work and holding positive attitudes about feedback in writing, may contribute to use of online writing tools. These two aspects of teaching match with positive Attitudes about feedback and Usefulness of feedback in undergraduate engineering. However, limited understanding of online writing tools may complicate perceptions of Ease of Use. This is an indication of the view to integrate writing in engineering education for learning purposes, a finding which was also observed in previous studies (Wheeler and McDonald 2000). However, while academics may hold positive views of writing, not all constructs of writing identified in this study may contribute to use of online writing tools. Beliefs are a combination of disciplinary and personal beliefs about teaching and learning, which may need to be explored before expectations that online writing tools are used in engineering are communicated through a faculty (Leydens and Schneider 2009; Alvarez et al. 2011).

To better understand interactions of Ease of Use, Usefulness and Attitudes, and the underlying constructs, this research will be extended in two ways. First, a limitation of the RGT 
method was the small sample size used to identify constructs and single item measurement of constructs in the questionnaire. As a result, the data presented in this discussion used in a largely descriptive manner and is not generalizable. To address these issues, and to increase power of the questionnaire, the constructs will be analysed for validity and reliability on a larger second set of data (> 100 participants) collected in 2015. Second, we have only presented an analysis of two academics in this paper. Two academics were chosen as an initial illustration of two contrasting views, based on the RGT constructs. Importantly, this only provides a limited view of possible beliefs about writing, but provides a simple demonstration of two different attitudes towards writing and possible implications for use of online writing tools. In the future, we will extend this analysis by including the additional seven academic interviews from this data collection and a second set collected later in 2014. A key area for further investigation will be the issue of writing being less motivating for students. Students' perceptions have a significant affect on how instructors design tasks and expectations of student performance.

The findings presented in this paper build on previous research (e.g. Jenkins, Jordan and Weiland 1993; Leydens and Schneider 2009; Wheeler and McDonald 2000) to address the international concern about writing in engineering. It provides in detail qualitative exploration of engineering academics' perceptions of writing; and further investigation of what this may mean for their adoption of online writing tools to support students' communication skills. Previously, there has been little empirical research considering engineering academics perceptions or use of writing in undergraduate subjects. While the findings are largely descriptive, they indicate where writing is believed to be most useful and how this may relate to students learning outcomes. Importantly, the integration of written tasks and assignments in engineering subjects should be specific to the disciplinary area and learning design. Future research in this area has the potential 
to provide better information about where this innovation can happen appropriately and with good affect on students' learning.

\section{References}

Aditomo, A., R. Calvo, and P. Reiman. 2011. "Collaborative Writing: Too Much of a Good Thing? Exploring Engineering sStudents' Perceptions Using the Repertory Grid." In Computer Supported Cooperative Learning, 128-135.

Ajzen, I. (1985). "From Intentions to Actions: A Theory of Planned Behavior." In J. Kuhl \& J. Beckmann (Eds.), Action Control SE - 2 (pp. 11-39). Springer Berlin Heidelberg.

Ajzen, I. 1991. "The Theory of Planned Behavior." Organizational Behavior and Human Decision Processes 50 (2): 179-211. doi:10.1016/0749-5978(91)90020-T.

Alvarez, I., A. Espasa, and T. Guasch. 2011. "The Value of Feedback in Improving Collaborative Writing Assignments in an Online Learning Environment." Studies in Higher Education 37 (4): 387-400. doi:10.1080/03075079.2010.510182.

Boiarsky, C. 2004. "Teaching Engineering Students to Communicate Effectively: A Metacognitive Approach." International Journal of Engineering Education 20 (2): 251260.

Calvo, R. A. (2015). Affect-aware reflective writing studios. In R. A. Calvo, S. K. D’Mello, J. Gratch, \& A. Kappas (Eds.), Handbook of Affective Computing (pp. 457-458). Oxford: Oxford University Press.

Calvo, R. A., O’Rourke, S. T., Jones, J., Yacef, K., and Reimann, P. (2011). Collaborative Writing Support Tools on the Cloud. IEEE Transactions on Learning Technologies, 4(1): 88-97.

Carter, M., M. Ferzli, and E. N. Wiebe. (2007). "Writing to Learn by Learning to Write in the Disciplines." Journal of Business and Technical Communication, 21 (3): 278-302. doi:10.1177/1050651907300466

Curtis, A. M., T. M. Wells, P. B. Lowry, and T. Higbee. (2008). "An Overview and Tutorial of the Repertory Grid Technique in Information Systems Research." The Communications of the Association for Information Systems 23: 38-62.

Davis, F. D. 1989. "Perceived Usefulness, Perceived Ease of Use, and User Acceptance of Information Technology." MIS Quarterly 13 (3): 319-340. doi:10.2307/249008. 
Drury, H., P. O’Carroll, and T. Langrish. 2006. "Online Appraoch to Teaching Report Writing in Chemical Engineering: Implementation and Evaluation." International Journal of Engineering Education 22 (4): 858-867.

Dunsmore, K., J. Turns, and J. M. Yellin. 2011. "Looking Toward the Real World: Student Conceptions of Engineering." Journal of Engineering Education 100 (2): 329-348. doi:10.1002/j.2168-9830.2011.tb00016.x.

Ellis, J. 2011. "Peer Feedback on Writing: Is On-line Actually Better than On-paper?" Journal of Academic Language \& Learning 5 (1): A88-A99.

Emig, J. (1977). "Writing as a Mode of Learning." College Compostion and Communication 28 (2): $122-128$.

Ertmer, P. A. (2005). "Teacher Pedagogical Beliefs: The Final Frontier in Our Quest for Technology Integration?" Educational Technology, Research and Development, 53 (4): 2540.

Figueiredo, A. D. 2008. "The Workshop on Philosophy and Engineering”, Royal Academy of Engineering, London, November 10-12,

Flick, U. 2000. "Episodic Interviewing." In Qualitative Researching with Text, Image and Sound, edited by M. Bauer and G., Gaskell, 75-92. London: SAGE Publications.

Ford, J. D., and L. A. Riley. 2003. "Integrating Communication and Engineering Education: A Look at Curricula, Courses, and Support Systems." Journal of Engineering Education 92 (4): 325-328. doi:10.1002/j.2168-9830.2003.tb00776.x.

Fransella, F., R. Bell, and D. Bannister. 2004. "A Manual for Repertory Grid Technique." Wiley.

Gassman, S. L., M. A. Maher, and B. E. Timmerman. 2013. "Supporting Students' Disciplinary Writing in Engineering Education." International Journal of Engineering Education 29 (5): $1270-1280$.

Heylen, C., and J. Vander Sloten. (2013). "A Technical Writing Programme Implemented in a first-year Engineering Course at KU Leuven." European Journal of Engineering Education, 38 (6): 595-607. doi:10.1080/03043797.2013.794201

Honey, P. (1979). "The Repertory Grid in Action." Industrial and Commercial Training, 11 (11): 452-459. doi:10.1108/eb003756

Karpova, E., A.-P. Correia, and E. Baran. 2009. "Learn to Use and Use to Learn: Technology in Virtual Collaboration Experience." The Internet and Higher Education 12 (1): 45-52. doi:10.1016/j.iheduc.2008.10.006.

Kelly, G. A. 1991. The Psychology of Personal Constructs. London: Routledge. 
Keynan, A., O. Ben-Zvi Assaraf, and D. Goldman. (2014). " The Repertory Grid as a Tool for Evaluating the Development of Students' Ecological System Thinking Abilities." Studies in Educational Evaluation, 41: 90-105. http://dx.doi.org/10.1016/j.stueduc.2013.09.012

Kwok, P.W. 2014. "The Role of Context in Teachers' Concerns about the Implementation of an Innovative Curriculum." Teaching and Teacher Education 38 (0): 44-55. doi:http://dx.doi.org/10.1016/j.tate.2013.11.002.

Lax, J. (2014). "Laying a foundation for academic writing in engineering: Helping international graduate students write in English." In Professional Communication Conference (IPCC), 2014 IEEE International (pp. 1-4). Pittsburgh: IEEE. doi:10.1109/IPCC.2014.7020353

Leydens, J. A., and J. Schneider. 2009. "Innovations in Composition Programs that Educate Engineers: Drivers, Opportunities, and Challenges." Journal of Engineering Education 98 (3): 255-271. doi:10.1002/j.2168-9830.2009.tb01023.x.

Lievens, J. (2012). "Debunking the Nerd Myth: Doing Action Research with First-year Engineering Students in the Academic Writing Class." Journal of Adacemic Writing 2 (1): 74-84.

Mitchell, B., and I. Geva-May. 2009. "Attitudes Affecting Online Learning Implementation in Higher Education Institutions." Journal of Distance Education 23 (1): 71-88.

Nair, C.S., and A. Patil. 2008, "Industry vs Universities: Re-engineering Graduate Skills - A Case Study." Australian Universities Quality Forum (AUQF), 16: 75-80.

Qiu, M., J. Hewitt, and C. Brett. 2014. "Influence of Group Configuration on Online Discourse Writing." Computers \& Education 71: 289-302. doi:10.1016/j.compedu.2013.09.010.

Rendahl, M., and L.-A. K. Breuch. (2013). "Toward a Complexity of Online Learning: Learners in Online First-year Writing." Computers and Composition, 30 (4): 297-314. doi:10.1016/j.compcom.2013.10.002

Rikakis, T., D. Tinappl, and L. Olson. 2013. "The Digital Culture Degree: A Competency-Based Interdisciplinary Program Spanning Engineering and the Arts." Frontiers in Education Conference, 2013 IEEE. doi:10.1109/FIE.2013.6685110.

Riley, L. A., P. Furth, and J. Zelmer. (2000). "Assessing Our Engineering Alumni: Determinants of Success in the Workplace." In 2000 ASEE/Gulf-Southwest Section Annual Conference.

Rolfe, V. 2011. "Can Turnitin Be Used to Provide Instant Formative Feedback?" British Journal of Educational Technology 42 (4): 701-710. doi:10.1111/j.1467-8535.2010.01091.x.

Straub, E. 2009. "Understanding Technology Adoption: Theory and Future Directions for Informal Learning." Review of Educational Research 79 (2): 625. 
Umbach, P., and S. Porter. 2002. "How Do Academic Departments Impact Student Satisfaction? Understanding the Contextual Effects of Departments." Research in Higher Education 43 (2): 209-234. doi:10.1023/A:1014471708162.

Venkatesh, V., and F. D. Davis. (2000). "A Theoretical Extension of the Technology Acceptance Model: Four Longitudinal Field Studies." Management Science, 46 (2): 186-204. doi:http://www.jstor.org/stable/2634758

Waycott, J., S. Bennett, G. Kennedy, B. Dalgarno, and K. Gray. (2010). "Digital Divides? Student and Staff Perceptions of Information and Communication Technologies." Computers \& Education, 54 (4): 1202-1211. doi:http://dx.doi.org/10.1016/j.compedu.2009.11.006

Wheeler, E., and R. L. McDonald. 2000. "Writing in Engineering Courses." Journal of Engineering Education 89 (4): 481-486. doi:10.1002/j.2168-9830.2000.tb00555.x. 